\title{
Short-term Efficacy of Dienogest in Improving Pain in Patients with Endometriosis: A Single-center Experience
}

\author{
(1D) Cihan Kaya, (1) İsmail Alay, (D) Hüseyin Cengiz, (1) Ece Bahçeci, (D) Murat Ekin, (D) Levent Yasar
}

University of Health Sciences Turkey, Bakirkoy Dr. Sadi Konuk Training and Research Hospital, Clinic of Obstetrics and Gynecology, Istanbul, Turkey

\section{Abstract}

Objective: Endometriosis is a common disease that affects 5\%-15\% of women of reproductive age. This study aimed to evaluate the effect of dienogest (DNG) on improving pain scores of patients with endometriosis.

Methods: Data of 77 women who were admitted to the endometriosis clinic from March 1, 2015, to March 1, 2017, were evaluated. Patients were divided into 2 groups: DNG group ( $n=46$ ) or group that denied use of any medication (expectant management group, $n=31$ ). The main presenting symptoms were graded using the visual analog scale (VAS). Age, parity, gravidity, body mass index (BMI), VAS scores, and further surgery requirement of the study groups were compared.

Results: The most common presenting symptom was dysmenorrhea (79.2\%), and the least common was dysuria (7.8\%). No statistically significant difference was found between the study groups in terms of age, parity, gravidity, BMI, and further surgery requirement. A significant difference was found in the reduction of dysmenorrhea, dyspareunia, dyschezia, and pelvic pain VAS scores between the study groups, and more reduction was observed in the DNG group after 6 months of follow-up ( $p<0.001, p=0.04, p=0.009$, and $p=0.01$, respectively).

Conclusion: DNG might be an alternative treatment for reducing pain symptoms related to endometriosis.

Keywords: Dienogest, endometriosis, pelvic pain, treatment outcome

\section{INTRODUCTION}

Endometriosis is an abnormal growth of endometrial tissue other than the inner uterine layer and affects approximately $10 \%$ of women of reproductive age. It is also observed in $70 \%$ of women with lower abdominal quadrant pain and $48 \%$ of patients with infertily $(1,2)$. In addition, it could cause severe dysmenorrhea, dysuria, dyspareunia, and even dyschezia (2). Till date, medical therapy has been widely recommended for pain relief and suppression of endometriotic lesions (3).

Combined oral contraceptives (COC) are well tolerated with their minimal metabolic effects and are commonly used to suppress ovulation and reduce menstrual blood flow in women with endometriosis (4). In addition, gonadotropin-releasing hormone analogs (GnRH-a) evoke pharmacological menopause by suppressing ovulation and reducing ovarian steroidogenesis. However, its extended use is restricted due to the risk of decreased bone mineral density (BMD) (5).

To treat endometriosis-related symptoms, progestins are prescribed owing to their effects of inhibiting ovulation, reducing serum levels of estrogen resulting in endometrial atrophy, and decreasing levels of peritoneal inflammatory markers (6). Although progestins, such as desogestrel and medroxyprogesterone acetate, might cause several androgen-related side effects, new-generation progestins, such as dienogest (DNG) which is a fourth-generation, well-tolerated, semisynthetic selective progestin that possess the pharmacological features of 19-nortestosterone, have greater specificity on binding to progesterone receptors (7) and offer a 
local effect on endometriotic lesions, with little androgenic, estrogenic, glucocorticoid, or mineralocorticoid activity $(8,9)$. Previous studies have reported that DNG not only suppressed ovulation and exerted antiproliferative effect, but also inhibited cytokine secretion in the stroma of endometrial cells, which leads to a reduction of endometriosis-related pain (10).

This study aimed to assess the effect of DNG on endometriosisrelated pain in comparison with expectant management.

\section{METHODS}

After ethical approval was obtained from our Bakirkoy Dr. Sadi Konuk Training and Research Hospital Clinical Research Ethics Committee (approval number: 2017/126), analysis of prospectively collected data of 77 patients diagnosed with endometrioma, confirmed by either ultrasonography or laparoscopic surgery, was performed. Patients who were admitted to our endometriosis outpatient clinic within the time period from March 2015 to March 2017 were evaluated retrospectively.

Basic clinical data such as age, parity, gravidity, body mass index (BMI), and further surgery requirement were derived from the patients' files and computer-assisted hospital database. The exclusion criteria were as follows: Presence of malignancy, bowel disease, history of bowel surgery, history of pelvic inflammatory disease, presence of any autoimmune diseases, discontinuation of medical treatment, and use of any hormonal or antiinflammatory or immune-regulatory medications in the previous 3 months.

After application of the exclusion criteria, the patients were divided into 2 groups: A group of patients who received a dose of $2 \mathrm{mg} /$ day of DNG beginning at the early follicular phase of menstruation (DNG group, $n=46$ ) and a group of patients who refused any medical treatment despite the presence of pain symptoms (expectant management group, $\mathrm{n}=31$ ).

The main presenting symptoms were dysmenorrhea, dyspareunia, dysuria, dyschezia, and chronic pelvic pain, which were graded using a visual analog scale (VAS). All patients were asked to complete VAS questionnaire at the 1 st month and at $6^{\text {th }}$ month follow-up visit to analyze their pain severity. The questionnaire used an 11-point numerical rating scale: 0 indicates painless state and 10 indicates the worst pain that they had ever experienced.

The study groups were compared in terms of age, gravidity, parity, BMI, main presenting symptom, and further surgery requirement. BMI was calculated as the ratio of weight $(\mathrm{kg})$ to the square of height $\left(\mathrm{m}^{2}\right)$. Pelvic pain was defined as non-cyclic pain lasting at least 6 months, appeared in various body parts, such as the pelvis and abdominal wall, and caused serious disability or led to medical care (11).

\section{Statistical Analysis}

Data analysis was executed with SPSS (IBM SPSS Statistics for Windows, Version 20.0; IBM Corp., Armonk, NY). Data were presented as the mean \pm standard deviation. A one-sample Kolmogorov-Smirnov test was performed to evaluate the distribution of variables. Student's t-test was used for the comparison of parametric variables, and the Mann-Whitney $U$ test, chi-square test, and Fisher's exact test were used to compare non-parametric variables. Dependent non-parametric values were also analyzed using Wilcoxon rank test to evaluate pain scores observed before treatment and after the follow-periods in both study groups. For all calculations, a $p$ value of $<0.05$ was considered statistically significant.

\section{RESULTS}

The mean age of the patients was $34 \pm 7.8$ years in the expectant management group and $32 \pm 7.27$ in the DNG group. The mean BMI was $24.46 \pm 3.74$ in the expectant management group and $23.56 \pm 4.87$ in the DNG group. No significant difference was found between the study groups with regard to age, parity, gravidity, BMI, and further surgery requirement. Basic clinical data of the patients are shown in Table 1. The most common presenting symptom was dysmenorrhea (79.2\%). The remaining symptoms were chronic pelvic pain (37.7\%), dyspareunia (31.2\%), dyschezia (19.5\%), and dysuria (7.8\%). No significant difference was found between the study groups in terms of the main presenting symptoms on admission. A significant difference was noted between the study groups in terms of the reduction in dysmenorrhea, dyspareunia, dyschezia, and pelvic pain VAS scores, and more reduction was observed in the DNG group at the end of the 6 -month follow-up period $(p<0.001, p=0.04$, $p=0.009$, and $p=0.01$, respectively) (Table 2 ). We also analyzed

\begin{tabular}{|l|l|l|l|}
\hline \multicolumn{4}{|l|}{ Table 1. Basic characteristics of the study population } \\
\hline & $\begin{array}{l}\text { Expectant } \\
\text { management group } \\
\text { (n=31) } \\
\text { mean } \pm \text { SD }\end{array}$ & $\begin{array}{l}\text { Dienogest } \\
\text { group } \\
\text { (n=46) } \\
\text { mean } \pm \text { SD }\end{array}$ & $\begin{array}{l}\mathbf{p} \\
\text { value }\end{array}$ \\
\hline Age (years) & $34 \pm 7.8$ & $32 \pm 7.27$ & 0.31 \\
\hline Gravidity & $0.93 \pm 1.12$ & $0.84 \pm 1.05$ & 0.73 \\
\hline Parity & $0.9 \pm 1.04$ & $0.69 \pm 0.86$ & 0.42 \\
\hline BMI (kg/m²) & $24.46 \pm 3.74$ & $23.56 \pm 4.87$ & 0.15 \\
\hline $\begin{array}{l}\text { Surgery after } \\
\text { treatment (n/\%) }\end{array}$ & $1(3.2 \%)$ & $7(15.2 \%)$ & 0.07 \\
\hline BMI: Body mass index, SD: Standard deviation & \\
\hline
\end{tabular}


pain scores observed before treatment and after follow-up periods in each study group. Although no significant difference was found in the expectant management group for pain scores before treatment and after the follow-up, a significant decrease in dysmenorrhea, dyspareunia, dischezia, and chronic pelvic pain, was found in the DNG group $(p<0.001, p=0.003, p=0.008$, and $p=0.001$, respectively) (Table 3 ).

\section{DISCUSSION}

Considering the detrimental effect of endometriosis surgery, many clinicians support the idea that medical treatment might

\begin{tabular}{|c|c|c|c|}
\hline & $\begin{array}{l}\text { Expectant } \\
\text { management } \\
\text { group } \\
(\mathrm{n}=31) \\
\text { mean } \pm \text { SD }\end{array}$ & $\begin{array}{l}\text { Dienogest } \\
\text { group } \\
(n=46) \\
\text { mean } \pm \text { SD }\end{array}$ & $\begin{array}{l}p \\
\text { value }\end{array}$ \\
\hline $1^{\text {st }}$ visit dysmenorrhea & $4.91 \pm 4.12$ & $6.73 \pm 3.39$ & 0.09 \\
\hline $2^{\text {nd }}$ visit dysmenorrhea & $4.41 \pm 3.96$ & $3.69 \pm 3.55$ & 0.43 \\
\hline $1^{\text {st }}$ visit dyspareunia & $1.16 \pm 2.68$ & $2.15 \pm 3.08$ & 0.14 \\
\hline $2^{\text {nd }}$ visit dyspareunia & $1 \pm 2.63$ & $1.37 \pm 2.27$ & 0.27 \\
\hline $1^{\text {st }}$ visit dyschezia & $0.71 \pm 1.95$ & $1.78 \pm 3.35$ & 0.17 \\
\hline $2^{\text {nd }}$ visit dyschezia & $0.71 \pm 1.95$ & $0.93 \pm 2.18$ & 0.51 \\
\hline $1^{\text {st }}$ visit dysuria & $0.60 \pm 2.20$ & $0.81 \pm 2.20$ & 0.21 \\
\hline $2^{\text {nd }}$ visit dysuria & $0.45 \pm 1.39$ & $0.45 \pm 1.39$ & 0.24 \\
\hline $1^{\text {st }}$ visit pelvic pain & $1.8 \pm 3.07$ & $2.45 \pm 3.20$ & 0.39 \\
\hline $2^{\text {nd }}$ visit pelvic pain & $1.74 \pm 2.90$ & $1.34 \pm 2.07$ & 0.89 \\
\hline $\begin{array}{l}\text { Reduction of } \\
\text { dysmenorrhea }\end{array}$ & $-0.48 \pm 1.20$ & $-0.43 \pm 3.08$ & $<0.01$ \\
\hline Reduction of dyspareunia & $-0.16 \pm 0.73$ & $-0.78 \pm 1.61$ & 0.04 \\
\hline Reduction of dyschesia & 0 & $-0.84 \pm 2.07$ & 0.009 \\
\hline $\begin{array}{l}\text { Reduction of urinary } \\
\text { symptom }\end{array}$ & 0 & $-0.34 \pm 1.35$ & 0.09 \\
\hline Reduction of pelvic pain & $-0.06 \pm 0.35$ & $-0.08 \pm 2.10$ & 0.01 \\
\hline \multicolumn{4}{|c|}{ VAS: Visual analog scale, SD: Standard deviation } \\
\hline
\end{tabular}

Table 3. Difference between endometriosis-related VAS scores for the DNG group at $1^{\text {st }}$ visit and $2^{\text {nd }}$ visit (6 $6^{\text {th }}$ month)

\begin{tabular}{|c|c|c|c|}
\hline & $\begin{array}{l}\text { 1st visit } \\
\text { (on admission) }\end{array}$ & $\begin{array}{l}2^{\text {nd }} \text { visit } \\
\text { (6th month) }\end{array}$ & $p$ value \\
\hline Dysmenorrhea & $6.73 \pm 3.39$ & $3.69 \pm 3.55$ & $<0.001$ \\
\hline Dyspareunia & $2.15 \pm 3.08$ & $1.37 \pm 2.27$ & 0.003 \\
\hline Dyschesia & $1.78 \pm 3.35$ & $0.93 \pm 2.18$ & 0.008 \\
\hline Dysuria & $0.80 \pm 2.20$ & $0.45 \pm 1.39$ & 0.06 \\
\hline Pelvic pain & $2.45 \pm 3.20$ & $1.34 \pm 2.07$ & 0.001 \\
\hline
\end{tabular}

be empirical, before any surgical intervention, by using analgesic and antiinflammatory drugs as the first-line therapy (12). In addition, COC pills and progestins, such as medroxyprogesterone acetate or norethisterone, are used as medical treatment and are known as safe, well-tolerated, inexpensive, and effective long-term treatment of endometriosis $(3,12)$. On the contrary, $\mathrm{GnRH}-\mathrm{a}$, levonorgestrel-releasing intrauterine system, or opioid analgesics should be considered for those women who are resistant to first-line therapies (13). However, GnRH-a regimens are associated with hypoestrogenism-related symptoms, such as vaginal atrophy and decreased BMD, that restrain its clinical use as a long-term therapy (5).

In previous studies, DNG, a fourth-generation, semisynthetic selective progestin, had been compared with a GnRH agonist such as buserelin, triptorelin, and leuprolide acetate, in terms of providing relief to pelvic pain and other endometriosis-related symptoms $(10,14-18)$. Considering overall side effects, all those studies revealed that DNG had comparable unintended results such as irregular vaginal bleeding, headache, breast tenderness, and weight gain.

A study compared DNG and 19-nortestosterone-derivative progestin norethindrone acetate (NETA) in women with endometriosis $(19,20)$ and found a statistically significant difference in the reduction of mean dysmenorrhea score in favor of the DNG group, but both NETA and DNG presented similar pain relief in women with deep endometriotic lesions. However, no significant improvements were observed in the quality of life scores or sexual functions $(21,22)$.

Two studies have evaluated the long-term use of DNG by up to 52-53 weeks (18) and reported that DNG clinically improved endometriosis-related symptoms with a decrease in VAS scores. In these studies, most patients experienced abnormal menstrual bleeding as a side effect $(16,18)$. In a 24 -week placebo-controlled, randomized, double-blind, phase 3 study by Lang et al. (23) the efficacy and safety of $2 \mathrm{mg} /$ daily DNG intake was evaluated in 255 Chinese women using endometriosis-associated pelvic pain (EAPP) score and safety variables including adverse events, laboratory parameters, bleeding patterns, and BMD. They concluded that a mean reduction in the EAPP score was well tolerated with few adverse events in favor of DNG and DNG had no effect on BMD levels after 24 weeks of treatment. Overall, in our study, we evaluated 6-month results of our study population and compared them with previous literature (23). We observed significantly improved endometriosis-related symptom scores when compared with the controls. Considering the significant reduction in dysmenorrhea, dyspareunia, dyschezia, and pelvic pain scores in our study, DNG 
might reduce the secretion of inflammatory cytokines or might reduce endometrial foci by ovulation suppression.

\section{Study Limitations}

As study limitations, we did not evaluate the side effects of DNG and its effect on endometrioma size. Our results should be supported by larger case series with longer follow-up periods.

\section{CONCLUSION}

In summary, $2 \mathrm{mg}$ daily intake of DNG is effective in the management of endometriosis, and DNG should be considered an alternative in alleviating pain in patients with endometriosis.

\section{Ethics}

Ethics Committee Approval: Bakirkoy Dr. Sadi Konuk Training and Research Hospital Clinical Research Ethics Committee (approval number: 2017/126).

Informed Consent: The written informed consent was obtained from all of the participants.

Peer-review: Externally peer-reviewed.

\section{Authorship Contributions}

Concept: C.K., I.A., H.C., Design: C.K., H.C., Data Collection or Processing: E.B., I.A., Analysis or Interpretation: M.E., L.Y., Literature Search: C.K., E.B. Writing: C.K.

Conflict of Interest: No conflict of interest was declared by the authors.

Financial Disclosure: The authors declared that this study received no financial support.

\section{REFERENCES}

1. Podgaec S, Rizzo LV, Fernandes LF, Baracat EC, Abrao MS. CD4(+) CD25(high) Foxp3(+) cells increased in the peritoneal fluid of patients with endometriosis. Am J Reprod Immunol 2012;68:301-8.

2. Giudice LC, Kao LC. Endometriosis. Lancet 2004;364:1789-99.

3. Vercellini $\mathrm{P}$, Crosignani $\mathrm{P}$, Somigliana E, Viganò $\mathrm{P}$, Frattaruolo MP, Fedele L. 'Waiting for Godot': a commonsense approach to the medical treatment of endometriosis. Hum Reprod 2011;26:3-13.

4. Vercellini P, Eskenazi B, Consonni D, Somigliana E, Parazzini F, Abbiati A, et al. Oral contraceptives and risk of endometriosis: a systematic review and meta-analysis. Hum Reprod Update 2011;17:159-70.

5. Olive DL, Pritts EA. Treatment of endometriosis. N Engl J Med 2001;345:266-75.

6. Crosignani P, Olive D, Bergqvist A, Luciano A. Advances in the management of endometriosis: an update for clinicians. Hum Reprod Update 2006;12:179-89.
7. Sitruk-Ware R, Nath A. The use of newer progestins for contraception. Contraception 2010;82:410-7.

8. Köhler G, Faustmann TA, Gerlinger C, Seitz C, Mueck AO. A dose-ranging study to determine the efficacy and safety of 1, 2, and $4 \mathrm{mg}$ of dienogest daily for endometriosis. Int J Gynaecol Obstet 2010;108:21-5.

9. Andres Mde P, Lopes LA, Baracat EC, Podgaec S. Dienogest in the treatment of endometriosis: systematic review. Arch Gynecol Obstet 2015;292:523-9.

10. Harada T, Momoeda M, Taketani $\mathrm{Y}$, Aso T, Fukunaga M, Hagino $\mathrm{H}$, et al. Dienogest is as effective as intranasal buserelin acetate for the relief of pain symptoms associated with endometriosis-a randomized, doubleblind, multicenter, controlled trial. Fertil Steril 2009;91:675-81.

11. Fuentes-Márquez P, Cabrera-Martos I, Valenza MC. Physiotherapy interventions for patients with chronic pelvic pain: A systematic review of the literature. Physiother Theory Pract 2019;35:1131-8.

12. Johnson NP, Hummelshoj L; World Endometriosis Society Montpellier Consortium. Consensus on current management of endometriosis. Hum Reprod 2013;28:1552-68.

13. Brown J, Kives S, Akhtar M. Progestagens and anti-progestagens for pain associated with endometriosis. Cochrane Database Syst Rev 2012;2012:CD002122.

14. Strowitzki T, Faustmann T, Gerlinger C, Seitz C. Dienogest in the treatment of endometriosis-associated pelvic pain: a 12-week, randomized, doubleblind, placebo-controlled study. Eur J Obstet Gynecol Reprod Biol 2010;151:193-8.

15. Cosson M, Querleu D, Donnez J, Madelenat P, Konincks P, Audebert A, et al. Dienogest is as effective as triptorelin in the treatment of endometriosis after laparoscopic surgery: results of a prospective, multicenter, randomized study. Fertil Steril 2002;77:684-92.

16. Strowitzki T, Marr J, Gerlinger C, Faustmann T, Seitz C. Dienogest is as effective as leuprolide acetate in treating the painful symptoms of endometriosis: a 24-week, randomized, multicentre, open-label trial. Hum Reprod 2010;25:633-41.

17. Strowitzki T, Marr J, Gerlinger C, Faustmann T, Seitz C. Detailed analysis of a randomized, multicenter, comparative trial of dienogest versus leuprolide acetate in endometriosis. Int J Gynaecol Obstet 2012;117:228-33.

18. Petraglia F, Hornung D, Seitz C, Faustmann T, Gerlinger C, Luisi S, et al. Reduced pelvic pain in women with endometriosis: efficacy of longterm dienogest treatment. Arch Gynecol Obstet 2012;285:167-73.

19. Muneyyirci-Delale 0, Anopa J, Charles C, Mathur D, Parris R, Cutler JB, et al. Medical management of recurrent endometrioma with long-term norethindrone acetate. Int J Womens Health 2012;4:149-54.

20. Ferrero S, Remorgida V, Venturini PL, Leone Roberti Maggiore U. Norethisterone acetate versus norethisterone acetate combined with letrozole for the treatment of ovarian endometriotic cysts: a patient preference study. Eur J Obstet Gynecol Reprod Biol 2014 Mar;174:117-22.

21. Vercellini P, Somigliana E, Consonni D, Frattaruolo MP, De Giorgi O, Fedele L. Surgical versus medical treatment for endometriosisassociated severe deep dyspareunia: I. Effect on pain during intercourse and patient satisfaction. Hum Reprod 2012;27:3450-9.

22. Agarwal S, Fraser MA, Chen I, Singh SS. Dienogest for the treatment of deep endometriosis: case report and literature review. J Obstet Gynaecol Res 2015;41:309-13.

23. Lang J, Yu Q, Zhang S, Li H, Gude K, von Ludwig C, et al. Dienogest for Treatment of Endometriosis in Chinese Women: A Placebo-Controlled, Randomized, Double-Blind Phase 3 Study. J Womens Health (Larchmt) 2018;27:148-55. 